\title{
The positive effect of the use of cues for learning forward rolls in children with learning difficulties
}

\author{
RAFAELA Z. F. COSTA ${ }^{1}$ | INARA MARQUES ${ }^{1}$ | LAÍSLA C. DA SILVA ${ }^{1}$ | JOSIANE MEDINA-PAPST ${ }^{1}$ | \\ ${ }^{1}$ Centro de Educação Física e Esporte, Universidade Estadual de Londrina, Londrina, PR, Brazil. \\ Correspondence to: Rafaela Zortéa Fernandes Costa, Rodovia Celso Garcia Cid, Pr445, Km380, Campus Universitário. Caixa postal 10.011, CEP: 86057-970, Londrina, PR, BRAZIL. \\ email: rafaela_zortea@hotmail.com \\ https://doi.org/10.20338/bjmb.v13i4.129
}

\section{HIGHLIGHTS \\ - The intervention with cues aided the learning stages progression. \\ - The intervention with cues aided the failures decrease of the skill. \\ - The learning cues are beneficial to the forward roll learning.}

\section{ABBREVIATIONS}

GLC group learning cues

GWC group without learning cues

ICC Intraclass Correlation Coefficient

LC learning cues

POS post-test

PRE pre-test

RET retention

SPSS Statistical Package for the Social

Sciences

PUBLICATION DATA

Received 18022019

Accepted 10052019

Published 01102019

\begin{abstract}
BACKGROUND: Research has demonstrated that learning difficulties are related to motor difficulties.
AIM: The objective of this study was to verify the effect of the use of learning cues in the performance development of forward rolls by children with learning difficulties.

METHOD: Twenty-six children (12 boys and 14 girls) aged 10-11 years old (mean aged $10.7 \pm 0.6$ years old) composed two groups: one with learning cues (GLC) and another without learning cues (GWC). The children were indicated by the school as they present learning difficulties in several academic areas and, therefore, attend reinforcement classes in the extra-curricular period at school. The study took place in four phases: Pretest; Intervention (five sessions, 45-minutes each); Post-test; Retention (two days post-test). For the motor performance analysis, the children were filmed and the videos were analyzed by two evaluators, using the motor pattern check list for the forward rolls.

RESULTS: Regarding GWC, no significant differences were found. On the other hand, GLC showed significant results during the evaluation phases.

CONCLUSION: This showed that the use of cues to teach forward rolls to children with learning difficulties was positive, demonstrating that learning cues are fundamental resources which teachers in the area can adopt.
\end{abstract}

\section{INTRODUCTION}

Researches have demonstrated the existence of a relationship between motor and cognitive development ${ }^{1}, 2$, and children with learning difficulties also present motor difficulties $2,3,4,5,6$. Recently, the number of studies interested in investigating factors related to these difficulties has increased.

Lopes et al. ${ }^{2}$ identified that in children, difficulties in gross motor skills, which require participation of larger muscle groups, such as running, jumping, etc., are associated with the child's cognitive functioning. According to the authors, the activation of the cerebellum and the frontal lobe play an important role in mediating between gross motor skills and cognitive functions, so that motor practice reinforces the neural network, resulting in the pre-activation of cortical activities that are responsible by cognitive functions.

Other studies also report to pronounced delay in the motor development of children with learning difficulties ${ }^{3}$, highlighting the compromised development of components related to body, spatial and temporal notions ${ }^{4}$. Specifically, regarding balance tasks, Silva and Beltrame ${ }^{5}$ observed that boys with learning difficulties in writing and 
reading presented worse results in performance of balance tasks compared to girls and boys with other types of learning difficulties. Amaro, Jatobá, Santos and Rosa Neto also reports that children with learning difficulties demonstrated greater difficulties in executing balance and temporal organization skills. From this perspective, it is known that balance motor skills are extremely important both in the sports and physical activity context, or even to move quickly and efficiently from one place to another in everyday activities ${ }^{7}$. In the scope of skills with this requirement, the forward roll is a skill applied in the context of gymnastics, which involves dynamic balancing ability, and children aged about seven years old should be able to master this skill.

Perotti Júnior and Pellegrini ${ }^{8}$ pointed out that, although the skill to roll is a motor pattern that very young children can perform on their first attempt, it is usually carried out in a disorganized way and with the presence of unnecessary movements. In general, it is stated that, throughout development, the child acquires some aspects of the skill, such as body alignment and speed, perfecting it progressively. However, it should be noted that failure in one of these aspects will influence the movement as a whole. Thus, for the individual reach high levels of performance, it is considered that guided practice and the use of efficient strategies are necessary ${ }^{9}$.

Studies such as those of Newell ${ }^{10}$ and Schmidt and Wulf11 emphasize the influence of several factors related to learning that can potentiate the acquisition of different skills, among which verbal and visual instructions are highlighted, indicating what the learner should do or how to carry out the action ${ }^{12}$. However, these instructions may be full of information, which would make it difficult to interpret and maintain long-term memory. For these processes to occur, selective attention is essential, because the process of choosing and selecting the relevant information to be processed depends on the involvement of the attention mechanisms to highlight the priority source of attention ${ }^{13}$.

Considering that different strategies have the objective of enhancing learning, instructions through cues are considered beneficial for the acquisition of motor skills by acting on the mechanisms of information processing. This strategy focuses the learner's attention on the important phases of the task, helping them to discard the irrelevant information present in the action ${ }^{14,15}$ and accelerating the transition between learning stages ${ }^{16}$. In this case, the emphasis is on control of the selective attention mechanisms of the performer, acting as a strategy that does not overload the learner with information. The objective of instructional cues is to provide simple and specific information related to the critical elements of the activity ${ }^{14,17}$.

The classic study conducted by Masser ${ }^{14}$ has already demonstrated favorable results from the use of cues and, among the abilities tested by the author, the learning of forward rolls stands out. Other studies that demonstrated a positive effect of the use of cues were conducted in the context of dance ${ }^{16}$, in the body perception improvement of children with a motor deficiency ${ }^{18}$, learning rhythmic gymnastics skills ${ }^{19}$, dive rolls ${ }^{20}$, field tennis ${ }^{21}$, and the Crawl swimming technique performed by hearing impaired individuals ${ }^{22}$.

It can be observed that learning cues present positive effects in different contexts and with different populations; however, it is barely known about their effect on the learning of children with academic learning difficulties. Such difficulties are understood as students' issues during the schooling period, specifically to the capture and assimilation of information ${ }^{5}$. Therefore, investigations into the effectiveness of this strategy in this population are necessary, mainly due to the great ease of cues usage in the teachinglearning process at scholar contexts ${ }^{23}$. Considering the learning difficulties of these 
children, this study questions whether the selected learning cues would have the potential to make the instructions clearer and more objective, so as to aid in the acquisition of these skills. Thus, the objective of the study was to conduct an intervention to test the effect of learning cues (LC) on the acquisition of forward rolls by children with learning difficulties.

To test this effect, the following hypotheses were considered: 1) children would learn the motor skill as an effect of practice, but the group with learning cues would maintain their performance after the intervention; 2) children who received learning cues would perform better compared to the group without cues.

\section{METHODS}

This study is characterized as almost experimental, without control group. It has methodological focus on the description and explanation of the effects of the use of cues in the learning process of forward rolls.

\section{Sample}

Twenty-six children (12 boys and 14 girls) aged 10,7 \pm 0,6 years old and enrolled in the municipal school of Cambé-PR composed two experimental groups: a group which did not receive learning cues (GWC) (mean aged $10.4 \pm 0.5$ years old) and a group which received learning cues (GLC) (mean aged $11.0 \pm 0.6$ years old) during learning of forward roll. The sample was formed by convenience, according to the proposed criteria fulfillment for the characterization of the groups.

The children were indicated by the school as they presented academic learning difficulties, such as on reading, writing, mathematics, language, task comprehension, or even on interpersonal relationship issues. In addition, these children attended the reinforcement period during the extra-curricular school hours. In order to isolate interference from contact between the children of different groups, each group belonged to a different school. All the children and their parents signed a Free and Informed Consent Term and the research was approved by the Ethics Committee in Research with Human Beings of the local University (Opinion no. 1,675,276). Table 1 describes the distribution of children regarding learning difficulties; information obtained from the school pedagogical team.

Table 1 - Characteristics of the groups regarding learning difficulties.

\begin{tabular}{lcccccc}
\hline & & \multicolumn{5}{c}{ Difficulties } \\
\hline Age & Reading & Writing & Mathematics & $\begin{array}{c}\text { Interpersonal } \\
\text { Relationships }\end{array}$ & Attention \\
\hline LC $(n=11)$ & $10 \pm 0.5$ & 3 & 2 & 1 & 2 & 3 \\
\hline S & $11 \pm 0.6$ & 7 & 4 & 1 & 2 & 1 \\
\hline
\end{tabular}

Source: The authors.

\section{Instruments}

The motor pattern checklist for forward rolls, proposed by Gallahue and Donnelly ${ }^{7}$, was used to evaluate the forward roll skill. This list includes three stages of skill development: a) initial stage; b) elementary stage; and c) mature stage, in which points are indicated for the observation of body segments throughout the skill performance. As the movement was delineated in stages, the learning evaluation was performed from 
observation of the items realization, being that, for the classification, the learner was required to present the highest number of items related to that stage. In addition to the skill stages, nine faults and/or difficulties were observed in the skill performance: 1) the head forcibly touches the mattress; 2) failure to properly bend the body ; 3 ) inability to push with the arms; 4) pushes with one arm; 5) failure to remain in a bent position; 6) inability to perform consecutive rolls; 7) feels dizzy; 8) failure to perform the roll in a straight line; and 9) loss of sufficient momentum to complete a circuit.

To film the children's performance during experimental phases (pre-test; post-test and retention; PRE, POS and RET, respectively) a Sony-brand digital camera, Handycam DCR-SR42 was used, with a $60 \mathrm{~Hz}$ sampling frequency and programmed automatic shutter speed.

For the intervention, the following equipment was used: large artistic gymnastics mattress, a foam ramp, a Pilates ball of size number 75, TNT strips, a \#10 ball, and a notebook to skill's video demonstration.

\section{Procedures}

The children's motor performance evaluation in the forward roll task was performed before (PRE) and after the intervention classes (POS), and in a third evaluation session (RET), conducted 48 hours after the POS. All sessions (PRE, POS, and RET) followed the same procedure, that is, the children watched a demonstration video of the skill twice and then made three attempts of the forward roll on a large artistic gymnastics mattress. In order to isolate interference from contact among children of different groups, each group belonged to a different school. After random separation of the groups (GWC and GLC) the children participated of an intervention program to learn the forward roll. The intervention consisted of five classes, three times a week, 45 minutes each, taught by the researcher with the help of a Physical Education teacher previously instructed about the procedures of each session. The activities planned for the intervention were progressively elaborated (from the simplest to the most complex), so children performed several exercises, such as rolling on a Pilates ball or rolling on a foam ramp, starting from the highest point. During the classes, the children were instructed about the exercises and watched the forward roll motor skill demonstration video before performing the task attempts. Each class consisted of four exercises, performed in a progressive way, at the end of each class, the children performed play activities, such as chase games and/or hopscotch.

GLC children received learning cues during intervention classes while GWC children did not received learning cues. During the intervention sessions, the GLC group received the LC in each session, after and before each practice. The LCs were provided in a way that all students could listen to them, thus ensuring that participants received the same number of cues.

The cues used teach the skill were directly related to specific points in the developmental stages, following the progressive order: "bend your body like a ball"; "try to keep your body in a straight line"; "keep your chin in your chest"; "keep your body bent tightly "; and "when you touch your feet on the ground, throw your arms forward to lift you".

\section{Statistical analysis}

In the present study, the classification of the skill in stages and the number of performance errors of each child were used to the analysis. In this way, the stages and 
failures number performed during the pre-test (PRE), post-test (POS), and retention (RET) phases were compared. The choice was made to use the faults concomitantly to the stages so that the changes in performance could be observed more efficiently, since improvement in performance would entail in a decrease in the errors number.

The performance was evaluated through the recorded images and analyzed by an examining board composed of two Physical Education specialists. The evaluators received the videos in random order in relation to the evaluation phases (PRE, POS, and RET) and in relation to the children.

The Intraclass Correlation Coefficient (ICC) was applied to verify the agreement between the evaluators in the observation of the stages and the faults presented by the children. Subsequently, the Mann-Whitney $U$ test was used to compare the stages and faults between the groups and the Friedman and Wilcoxon post-hoc test was used for the comparison among phases (PRE, POS, and RET). The Statistical Package for the Social Sciences - SPSS for Windows - (Version 13.0, SPSS Inc. @, Chicago, Illinois) was used, with a significance level of $p<0.05$.

\section{RESULTS}

After analysis of the videos, it was verified the agreement between the evaluators in the observation of the stages and faults presented by the children, with a high correlation (Stages, ICC $=0.81$ and $p=0.001$; Faults, ICC $=0.96$ and $p=0.001$ ). In relation to the frequency of children classified into the different stages during the phases, it can be observed that there was an increase of children classified in the mature stage of the forward roll skill development in the GLC (POS $n=12$ and RET $n=12$ ). In the GWC, there was little change over the phases (Table 2).

Table 2 - Absolute frequency and relative frequency of children classified in the stages throughout the phases in each group.

\begin{tabular}{ccccc}
\hline Group & Stage & Pre-test & Post-test & Retention \\
\hline \multirow{2}{*}{ GWC } & Initial & $2(18.2 \%)$ & $2(18.2 \%)$ & $2(18.2 \%)$ \\
& Elementary & $6(54.5 \%)$ & $7(63.6 \%)$ & $6(54.5 \%)$ \\
& Mature & $3(27.3 \%)$ & $2(18.2 \%)$ & $3(27.3 \%)$ \\
\hline \multirow{2}{*}{ GLC } & Initial & $2(13.3 \%)$ & $2(13.3 \%)$ & $1(6.7 \%)$ \\
& Elementary & $11(73.3 \%)$ & $1(6.7 \%)$ & $2(13.3 \%)$ \\
& Mature & $2(13.3 \%)$ & $12(80.0 \%)$ & $12(80.0 \%)$ \\
\hline
\end{tabular}

Source: The authors.

In the comparison between the groups (GWC and GLC) regarding stage classification, there were no differences in the PRE phase $(U=76.00, p=0.76)$, but a difference was observed in the POS $(U=37.50, p=0.01)$ and RET $(U=40.00, p=0.02)$, in a manner that in the GLC there was a higher frequency of children with more advanced stages of the skill compared to the GWC.

Regarding the GWC, there were no statistically significant differences over the phases (PRE, POS, and RET) in the classification of the stages $(p=0.36)$ or the number of faults $(p=0.25)$. Differently, in the GLC, there were significant results over the phases (PRE, POS, and RET), both in the classification of the stages $(p=0.00)$, with a significant improvement in the performance from PRE to RET $(p=0.05)$ and in the number of faults 
$(p=0.00)$, with a significant improvement from the PRE to POS phase $(p=0.02)$ and from PRE to RET ( $p=0.02$ ). This demonstrates that the learning cues were effective to improve the skill performance, which was maintained even after the practice was finished, characterizing thus, the forward roll learning (Figure 1).

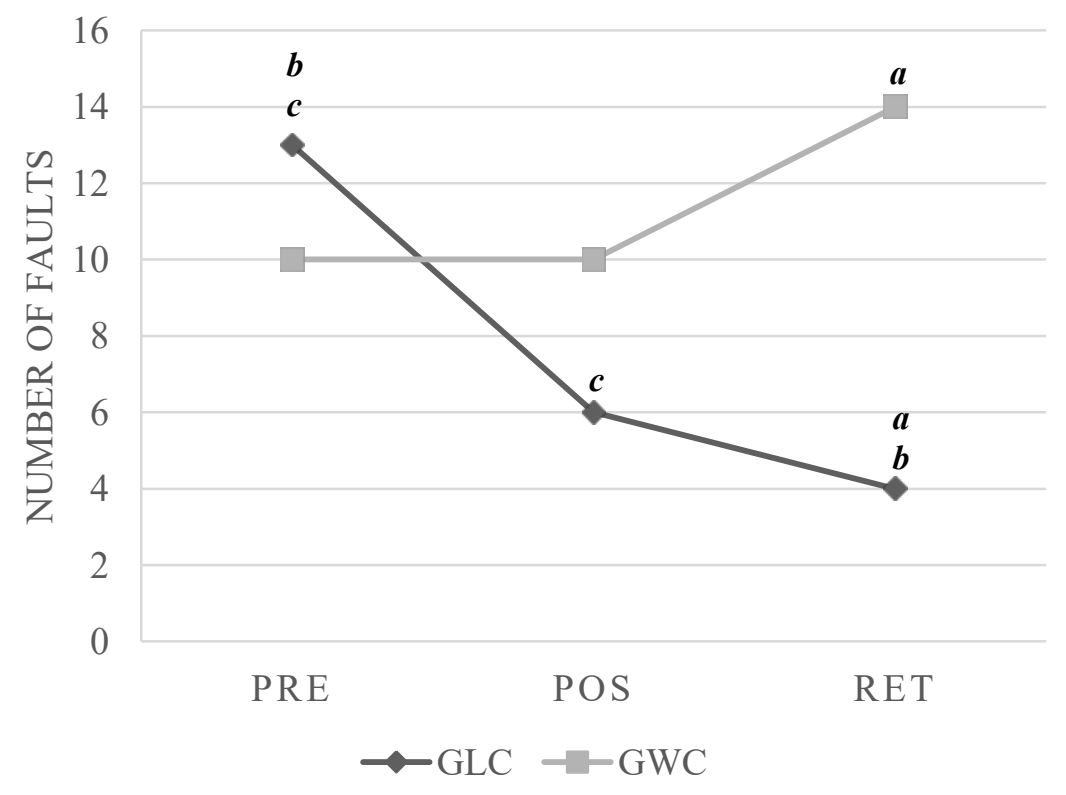

Figure 1. Median of the faults of each group during the PRE, POS, and RET phases. * ${ }^{*}, b, c=p=0.001$. Source: The authors

The number of faults comparison between groups has not demonstrated significant differences in the PRE $(U=63,50 ; p=0.33)$ and POS phases $(U=57.00 ; p=$ $0.19)$, only in the RET phase $(U=44.00 ; p=0.04)$ in which the $G L C$ presented lower number of faults compared to the GWC. In the comparison among the phases there was a significant decrease in the GLC's number of faults from PRE to POS $(p=0.02)$ and from PRE to RET ( $p=0.02$ ). On the other hand, the GWC presented a descriptive increase in the number of errors from the POS to the RET phase.

\section{DISCUSSION}

The present study tested the effect of specific cues for verifying forward roll learning by children with learning difficulties at the school setting. The results demonstrated skill learning by children who received LC (GLC), demonstrated by the increase in the number of children classified in the mature stage of the skill development (PRE $=2 ; \mathrm{POS}=12 ; \mathrm{RET}=12$ ) and a decrease in the number of faults over the phases (PRE = 13; POS = 6; RET = 4). These results allow us to conclude that the cues provided critical information to learn the skill in a short time of practice, supporting the idea that this strategy assists students in selecting relevant information without overloading them at the instruction time. These results reaffirm the findings in the literature, highlighting that LCs have the potential to maximize the learning of the proposed motor skill ${ }^{15}$. 
It is worth mentioning that although the GLC presented different performance from the GWC at PRE, there was no significant difference in this phase, neither in relation to the stages $(U=76.00, p=0.76)$ nor in relation to the number of faults $(U=63.50 ; p=0.33)$.

It was observed that the GWC has not demonstrated improved performance, neither in stage classification nor in relation to the number of faults, despite performing the same practical activities during the five intervention sessions. It was found that this group, at the end of the practice, presented an increased number of faults, whereas the GLC presented a reduced number of faults even after the practice ended, demonstrating the beneficial and long-lasting effect of learning cues.

These results corroborate the findings of Caçola and Ladewigig in a study for the learning of throwing a ball followed by rolling forward and recovery with the feet on the ground, using only six intervention sessions, thus confirming the cues usage beneficial effect for the acquisition of the forward roll skill, minimizing the learning time.

Even considering the specificities of the studied sample, it can be stated that the learning difficulties have not presented obstacles to the effective use of the cues, allowing improvement in the motor pattern of the skill and a significant decrease in the number of faults. Thus, we can affirm the beneficial effect of the cues usage for children with learning difficulties focused on the specific aspects of the action, in order to directly influence the learning of the skill and to potentiate the practice, reducing overload on the attention processes ${ }^{15}$. It is worth noting that the learning difficulties presented in this study refer to specific contents (reading, writing and mathematics) or behavioral order (attention and interpersonal relationship issues), which suggests a deeper understanding taking into account all the specificities of this population.

Other studies testing the effect of LCs with more specific populations, such as Medina et al. ${ }^{20}$, who aimed to evaluate learning in the acquisition of dive rolls by children with Developmental Coordination Disorder, did not find a positive effect after seven intervention classes. The authors concluded that the learning cues used did not present information relevant enough for significant improvement in children's motor performance, suggesting that, although effective, cues should be elaborated and adapted to the specific characteristics of the learners.

The fact that LCs presented positive effects for the learning of the forward roll in the present study confirm the study's hypotheses and reinforce the suggestion that for this strategy to be effective, they should focus on the essential elements of the skill to be learned. In this way, the teacher/instructor must know the specificities of the task and learners so that they can provide the most adequate cues to achieve the desired goal14,23. By this way, the results of the present study add important information regarding the usage of cues and its effectiveness for teaching children with learning difficulties and the possibilities of using it at school context. Regardless the difficulty kinds, these children need a different look and, it seems, that the learning cues can be good strategies for teaching motor skills to this population.

As this was an intervention realized in groups, to control all intervening variables in a learning process of this nature was impossible, such as the number of times the child observed their friends performing the skill, and the possible practice of similar abilities in other school activities or even at home. It is also worth noting that the instrument used for the evaluation of learning is not a validated and proposed instrument for research purposes. However, there are available studies in the literature that have used this method to observe changes in the performance with experience in the task ${ }^{24,25}$. It should be 
emphasized that these aspects do not detract from the found results, but reinforce the need for further studies using this strategy (learning cues), since it can contribute to the work of the Physical Education professional aiming to help students to learn different motor skills.

It is considered that future studies should be carried out with different populations, allowing greater comparisons of the cues effects on this basic skill learning, without ruling out the context of usage in the school environment by Physical Education teachers.

\section{CONCLUSION}

Based on the results of the present study, it was concluded that LCs were beneficial for learning the forward roll by children with learning difficulties, minimizing the time taken to learn the proposed motor skill. It is emphasized that the cues need to focus on the essential elements of the skill and their usage should take into account the learners' characteristics. It is considered that this strategy should be investigated in future studies, especially considering its easy use in learning contexts, mainly at school environments.

\section{REFERENCES}

1. Diamond A. Close interrelation of motor development and cognitive development and of the cerebellum and prefrontal cortex. Child Dev. 2000; 71:44-56.

2. Lopes L, Santos R, Pereira B, Lopes VB. Associations between gross motor coordination and academic achievement in elementary school children. Hum Mov Sci. 2013; 32: 9-20.

3. Rosa Neto F, Almeida GML, Caon G, Ribeiro J, Carom JA, Piucco EC. Desenvolvimento motor de crianças com indicadores de dificuldades na aprendizagem escolar. Rev Bras Ciênc e Mov. 2006; 15(1): 45-51.

4. Medina-Papst J, Marques I. Avaliação do desenvolvimento motor de crianças com dificuldades de aprendizagem. Revista Brasileira Cineantropometria do Desempenho Humano. 2010; 12(1): 36-42.

5. Silva J, Beltrame, TS. Desempenho motor e dificuldades de aprendizagem em escolares com idades entre 7 e 10 anos. Motricidade. 2011; 7(2): 57-68.

6. Amaro KM, Jatobá L, Santos APM, Rosa Neto F. Desenvolvimento motor em escolares com dificuldades na aprendizagem. Movimento e Percepção. 2010; 11(16): 39-47.

7. Gallahue DL, Donnelly FC. Developmental physical education for all children. 4th ed. Human Kinetics, 2007.

8. Perotti Júnior A, Pellegrini AM. Organização espaço temporal do rolamento para frente. Movimento. 2001; 7 (15): 9-20.

9. Thelen E. Motor development: a new synthesis. American Phychologist. 1995; 50(2): 7995.

10. Newell KM. Coordination, control and skill. In: Goodman D, Wilberg RB, Franks I. (Eds.), Differing perspectives in motor learning, memory and control. Elsevier Science. 1985; 299317. 
11. Schmidt RA, Wulf G. Continuous concurrent feedback degrades skill learning: implications for training and simulation. Hum Factors. 1997; 39(4): 509-525.

12. Públio NS, Tani G, Manoel EJ. Efeitos da demonstração e instrução verbal na aprendizagem de habilidades motoras da ginástica olímpica. Rev Bras de Educ Fís Esp. 1995; 9 (2). Available in < http://cev.org.br/biblioteca/efeitos-demonstracao-instrucaoverbal-aprendizagem-habilidades-motoras-ginastica-olimpica/ >. Access in: 09/02/2019.

13. Johnston WA, Dark VJ. Selective attention. Ann Rev Psychol. 1986; 37: 43-75.

14. Masser LS. Critical cues help first-grade students' achievement in hands and forward rolls. Journal of teaching in physical education. 1993; 12: 301-312.

15. Medina-Papst J, Marques I, Ladewig I. Dicas de aprendizagem na aquisição de habilidades motoras: uma revisão. Rev Educ Fís. 2009; 20(4): 625-635.

16. Moura DKR. $O$ uso de dicas de aprendizagem no ensino de habilidades da dança moderna. [Dissertation] Universidade Federal do Paraná, Curitiba; 2006.

17. Souza MS, Spessato BC, Valentini NC. Estratégias de aprendizagem e o ensino do judô para iniciantes: demonstrações, dicas verbais e feedback. Revista Acta Brasileira do Movimento Humano. 2014; 4(5): 32-46.

18. Bertoldi ALS. A influência do uso de dicas de aprendizagem na percepção corporal de crianças portadoras de Deficiência Motora. [Dissertation] Universidade Federal do Paraná, Curitiba, 2004.

19. Caçola PM, Ladewig I. Comparação entre as práticas em partes e como um todo e a utilização de dicas na aprendizagem de uma habilidade da ginastica rítmica. Rev Bras Ciên Mov. 2007; 15(4): 79-86.

20. Medina J, Marques I, Ladewig I, Rodacki AM. $O$ efeito de dicas de aprendizagem na aquisição do rolamento peixe por crianças com TDC. Rev bras ciênc Esporte. 2008; 29(2): 79-94.

21. Boell IB, Yamaguchi AYS, Ladewig I, Spinelli AH, Franz LGC. O efeito das dicas de aprendizagem do forehand para crianças com características de déficit de atenção. Pensar prát. 2017; 20 (2): 268-281.

22. Passeto SC, Araújo PF, Corrêa UC. Efeitos de dicas visuais na aprendizagem do nado crawl para alunos surdos. Revista Portuguesa de Ciência do Desporto. 2006; 6(3): 281 293.

23. Silveira SR, Basso L, Freudenheim AM, Corrêa UC, Ferreira MG, Tani G. Aquisição da habilidade motora rebater na Educação Física escolar: um estudo das dicas de aprendizagem como conteúdo de ensino. Rev Bras Educ Fís Esp. 2013; 27(1): 149-57.

24. Maforte JPG, Xavier AJM, Neves LA, Cavalcante APC, Albuquerque MR, Ugrinowitsch H, Benda RN. Análise dos padrões fundamentais de movimento em escolares de sete a nove anos de idade. Rev Bras Educ Fís Esp. 2007; 21(3): 195-204.

25. Silva PT. Análise dos estágios de desenvolvimento das habilidades motoras fundamentais: um estudo com escolares com 9 e 10 anos. FIEP BULLETIN. 2014; 84, ed especial. 
Citation: Costa RZF, Marques I, Silva LC, Medina-Papst J. The positive effect of the use of cues for learning forward rolls in children with learning difficulties. BJMB. 2019: 13(4): 94-103.

Editor: Dr Fabio Augusto Barbieri - São Paulo State University (UNESP), Bauru, SP, Brazil; Dr José Angelo Barela São Paulo State University (UNESP), Rio Claro, SP, Brazil; Dr Natalia Madalena Rinaldi - Federal University of Espírito Santo (UFES), Vitória, ES, Brazil.

Copyright: @ 2019 Costa, Marques, Silva and Medina-Papst and BJMB. This is an open-access article distributed under the terms of the Creative Commons Attribution-NonCommercial-NoDerivatives 4.0 International License which permits unrestricted use, distribution, and reproduction in any medium, provided the original author and source are credited.

Funding: There was no funding for this study.

Competing interests: The authors have declared that no competing interests exist.

DOI: https://doi.org/10.20338/bjmb.v13i4.129 